\title{
INCLUSÃO DIGITAL E OS PRINCIPAIS DESAFIOS EDUCACIONAIS BRASILEIROS
}

\author{
INCLUSIÓN DIGITAL Y LOS PRINCIPALES DESAFIOS DEL SISTEMA \\ EDUCATIVO BRASILEÑO
}

\author{
DIGITAL INCLUSION AND THE MAIN CHALLENGES IN THE BRAZILIAN \\ EDUCATION
}

\author{
Cláudia PRIOSTE ${ }^{1}$ \\ Darcy RAIÇA ${ }^{2}$
}

RESUMO: O acesso às Tecnologias da Informação e Comunicação tem aumentado por parte da população brasileira. Porém, segundo o ranking de inclusão digital estabelecido pela ITU (2015), o Brasil ainda apresenta importantes defasagens em relação aos demais países avaliados. Em face dessa problemática, o presente artigo tem o objetivo de analisar os desafios da inclusão digital na educação brasileira, buscando compreender seus impasses. Pautamo-nos por uma metodologia de pesquisa qualitativa, exploratória, por meio da qual cotejamos dados de pesquisas nacionais e internacionais. A análise foi estabelecida a partir de sete indicadores: conectividade, capacitação, conteúdo, confiança, continuidade, letramento, e inclusão das pessoas com deficiência. Os resultados sugerem que a inclusão digital tem sido limitada, sobretudo em decorrência de problemas na qualidade da educação. Sem uma formação escolar consistente, os usos das TIC voltam-se sobretudo ao consumo e ao entretenimento. Concluiu-se que as escolas públicas brasileiras enfrentam sérias defasagens de infraestrutura tecnológica e de apoio ao docente; nesse contexto, a exclusão das pessoas com deficiência também se perpetua. Problemas na alfabetização e letramento constituem importantes obstáculos para uma devida apropriação dos recursos tecnológicos em prol de melhores condições de vida e participação social.

PALAVRAS-CHAVE: Inclusão digital. Letramento digital. Tecnologias da informação e comunicação na educação. Fosso digital. Tecnologia e educação.

RESUMEN: El acceso a las Tecnologías de la Información y Comunicación han aumentado por parte de la población brasileña. Sin embargo, según el ranking de inclusión digital establecidos por la ITU (2015), Brasil aún presenta desfase con relación a los demás países evaluados. Frente a esta problemática, el presente artículo tiene como objetivo analizar los desafíos de la inclusión digital en la educación

\footnotetext{
${ }^{1}$ Universidade Estadual Paulista (Unesp), Araraquara - SP - Brasil. Departamento de Psicologia da Educação da Faculdade de Ciências e Letras de Araraquara. Professora Assistente. Doutora em educação. Coordenadora do grupo de pesquisa “A formação do sujeito na era digital”. E-mail: claudiaprioste@gmail.com.

${ }^{2}$ Pontifícia Universidade Católica de São Paulo (PUC) - São Paulo -SP - Brasil. Professora Titular aposentada pela, docente dos cursos de Pós-Graduação em Educação da PUC-SP. E-mail: darcyraica@yahoo.com.br
} 
brasileña, buscando comprender sus estancamientos. Nos guiamos por una metodología de investigación cualitativa, exploratoria, por la cual cotejamos datos de investigaciones nacionales e internacionales. El análisis ha sido establecido a partir de siete indicadores: conectividad, capacitación, contenido, confianza, continuidad, literacía, e inclusión de personas con discapacidad. Los resultados sugieren que la inclusión digital ha sido limitada, sobretodo en consecuencia de los problemas en la calidad de la educación. Sin una formación escolar consistente, los usos de las TIC se vuelven sobre todo al consumo y al entretenimiento. Se concluye que las escuelas públicas brasileñas enfrentan serios desfases de infraestructura tecnológica y de apoyo al docente, en ese contexto, la exclusión de personas con discapacidad también se mantiene. Problemas en la alfabetización y literacía constituyen importantes obstáculos para una debida apropiación de los recursos tecnológicos en favor de mejores condiciones de vida y participación social.

PALABRAS CLAVES: Inclusión digital. Literacía digital. Tecnologías de la información y comunicación en la educación. Foso digital. Tecnología y educación.

ABSTRACT: The access to Information and Communication Technologies (ICT) has increased within the Brazilian population. However, according to the digital inclusion ranking established by ITU (2015), Brazil still presents important gaps in comparison to other evaluated countries. In view of this problem, the present article aims at analyzing the challenges of the digital inclusion in the Brazilian education, looking into understanding its obstacles. This study has grounds in a qualitative, exploratory research methodology, through which data of national and international researches were collected. The analysis was established based in seven indicators: connectivity, capability, content, confidence, continuity, literacy, and the inclusion of people with disabilities. The results suggest that the digital inclusion has been limited, mostly due to problems in the education quality. Without a consistent educational background, the use of ICTs is mostly directed to consumption and entertainment. It was concluded that Brazilian public schools face serious gaps of technological infrastructure and teacher support. In this context, the exclusion of people with disabilities also perpetuates. Problems in the basic literacy processes are important obstacles for proper technological resources appropriation in favor of better life conditions and social participation.

KEYWORDS: Digital inclusión. Digital literacy. Information and communication technologies. Digital divide. Technology and education.

\section{Introdução}

A inclusão digital impõe, peremptoriamente, novos desafios à educação escolar, ao mesmo tempo em que tem potencial para ampliar as perspectivas de ensino e de aprendizagem. Acessar e usufruir dos benefícios promovidos pelas Tecnologias da Informação e Comunicação (TIC) constitui importante condição para a apropriação de bens culturais e exercício da cidadania; contudo, no Brasil, ainda enfrentamos 
significativos desafios. De acordo com o Comitê Gestor da Internet (CGI), as escolas públicas brasileiras possuem insuficientes recursos tecnológicos para a condução de atividades pedagógicas (COMITÊ GESTOR DA INTERNET NO BRASIL, 2013a). Além disso, a baixa qualidade do ensino interfere significativamente na capacidade de uso das TIC quando se trata de ampliação dos conhecimentos, de melhoria das condições de vida, bem como de maior participação social.

$\mathrm{Na}$ última década, houve importante avanço no acesso às TIC por parte dos brasileiros, com maior popularização de televisões, computadores, telefones móveis e Internet. Em 2008, apenas 25\% dos domicílios possuíam computadores e $18 \%$ acessavam a Internet; em 2014 essas proporções duplicaram para 50\% e 51\%, respectivamente. Esse crescimento é um grande passo rumo à inclusão digital, contudo, ainda há inúmeros fossos digitais decorrentes de desigualdades regionais e de classe social. A presença de computador e de internet nos domicílios das regiões Sudeste e Sul é significativamente maior do que do Nordeste e Norte. Nas classes D e E somente 13\% das residências possuem computador. Estima-se que aproximadamente 27,3 milhões de domicílios não possuem computador, nem acesso à internet (COMITÊ GESTOR DA INTERNET NO BRASIL, 2015).

No ranking de inclusão digital realizado pela International Telecommunication Union (ITU), o Brasil ocupou, em 2014, a 61 ${ }^{\text {a }}$ posição; as primeiras colocações são respectivamente da Coréia do Sul, Islândia, Dinamarca, Reino Unido, Luxemburgo e Suíça, países que também se destacam nas avaliações internacionais em educação. A classificação de inclusão digital é realizada pela ITU desde 2008, baseando-se em indicadores que medem a infraestrutura de acesso às TIC, assim como as habilidades, a capacidade de obtenção de benefícios e seu impacto no rendimento. A análise da ITU demonstra que o Brasil está melhorando em termos de acesso e infraestrutura, porém no quesito que mede habilidades estamos piorando; se em 2012 estávamos na 72a . posição, em 2014 caímos para 81․ (INTERNATIONAL TELECOMMUNICATION UNION, 2015). Essa queda do indicador que mede habilidades está relacionada à baixa qualidade na educação, incluindo referências de taxas de analfabetismo da população. Em síntese, se de um lado, o Brasil tem avançado significativamente em termos de acessibilidade às TIC, de outro, há dúvidas no que tange à inclusão digital efetiva e transformadora da realidade social.

Diante desse contexto, o presente artigo tem como objetivo discutir os principais desafios da inclusão digital no âmbito educacional a partir de recentes pesquisas 
nacionais e internacionais sobre a temática, visando, assim, oferecer contribuições teóricas para que se possa pensar a inclusão digital a partir de novas premissas.

\section{A globalização e as TIC}

O fenômeno da globalização possui estreita conexão com o desenvolvimento das TIC, e tem suscitado polêmicas com relação ao possível aumento das desigualdades sociais. De acordo com a análise de Duarte (2007), a globalização é um processo em curso, que teve início na década de 1990, mobilizado pelas profundas transformações oriundas das tecnologias da comunicação. Muito embora ainda não se tenha um juízo formado sobre esse processo, Duarte (2007) considera que ele não se restringe aos aspectos econômicos e políticos, afetando nossas vidas de maneira persistente e profunda.

Giddens (2007) sustenta que a globalização foi influenciada pelos sistemas de comunicação do final da década de 1960, especialmente, pelo lançamento do primeiro satélite comercial. Desde então, os meios de comunicação de massa passaram a influenciar a estrutura de vida das pessoas de qualquer classe social. Segundo Giddens (2007, p. 22):

\footnotetext{
A comunicação eletrônica instantânea não é apenas um meio pelo qual notícias ou informações são transmitidas mais rapidamente. Sua existência altera a própria estrutura de nossas vidas, quer sejamos ricos ou pobres. Quando a imagem de Nelson Mandela pode ser mais familiar que o rosto de nosso vizinho de porta, alguma coisa mudou na natureza da experiência cotidiana.
}

Além dos efeitos da incomensurável troca de informações e de uma tendência à homogeneização da cultura, a globalização também contribui para o aumento da concentração de renda. Por outro lado, o sociólogo argumenta que esse fenômeno não pode ser avaliado apenas em uma perspectiva unidimensional, uma vez que a difusão de informações ao redor do mundo contribui também para ações afirmativas de identidades culturais locais e para uma espécie de colonização às avessas.

$\mathrm{Na}$ perspectiva de Baumam (1999), a aparente liberdade de movimento desencadeada pelos processos globalizantes não redundam em maior distribuição de riquezas entre diferentes culturas, pois a reestratificação social mantém privilégios e carências, assim, “o que é livre para alguns abate-se sobre outros como um destino 
cruel" (BAUMAN, 1999, p. 79). As novas tecnologias e a globalização do capital podem ampliar a mobilidade de uns, daqueles que estão no topo da hierarquia, enquanto as camadas inferiores continuam marcadas por restrições.

A crença em relação às redes computacionais globais possibilitarem maior participação democrática não resiste ao fato de que um poder transnacional tem se concentrado em determinados centros geopolíticos. Para Sassen (2010), algumas nações, particularmente os Estados Unidos e o Reino Unido, estão produzindo modelos de novos padrões e legalidades necessárias para conferir proteções e garantias às empresas e mercados globais, o que interfere na autoridade e política econômica de outros Estados. Deste modo, muitos Estados perdem autoridade no jogo econômico da globalização, enquanto alguns outros poucos ganham.

Segundo Duarte (2007), essa interconexão global do capitalismo neoliberal, aumentando a concentração de renda e a dissimetria de poderes, tem levado ao risco de uma exclusão crônica, a qual ameaça tanto os países do terceiro mundo quanto a população economicamente desfavorecida dos países desenvolvidos. Em sua visão, o aumento da penetração das tecnologias na vida cotidiana, sob o lastro de uma política neoliberal ideologicamente direcionada aos interesses dos grandes oligopólios, estaria contribuindo para intensificar as desigualdades sociais. Nesse contexto, o aumento de acesso às TIC não significaria, necessariamente, maiores oportunidades de inclusão social, sobretudo para as populações desprovidas de uma formação educacional consistente.

\section{Fosso digital e a e-inclusion}

A correlação entre exclusão social e digital tem sido reafirmada por diversos pesquisadores, como: Almuwil, Weerakkody e El-Haddadeh (2011), Kaplan (2005), Livingstone e Helsper (2008) e Mancinelli (2007). Para Kaplan (2005), não obstante o intenso crescimento e penetração das TIC em todos os grupos sociais, o fosso digital ainda permanece enorme devido principalmente à heterogeneidade de usos realizados por grupos socioeconômicos distintos. Mancinelli observa que: "não há um fosso digital, mas múltiplos fossos, os quais estão relacionados a uma variedade de fatores tais como: gênero; idade; agrupamentos étnicos; incertezas de vida e condições financeiras; bem como insegurança social e no trabalho" (2007, p. 2, tradução nossa). Na perspectiva de Livingstone e Helsper (2008), as barreiras para inclusão digital são 
graduais e estão fortemente associadas aos processos de exclusão no seio da sociedade, confirmados por diversos estudos demonstrando que os indivíduos com maior acesso às TIC tendem a possuir maior escolaridade, maior renda e status profissional do que aqueles que não possuem acesso. Nesse mesmo sentido, Almuwil, Weerakkody e ElHaddadeh (2011) argumentam que o debate sobre o fosso digital não deve ser concebido meramente como falta de acesso ou de uso das tecnologias. Os autores revelam ainda a tendência de mudança de foco conceitual de digital divide - termo normalmente traduzido para o português por fosso digital -, para o e-inclusion, pois digital divide teria um enfoque restrito à dimensão do acesso, enquanto o termo $e$ inclusion seria mais amplo, incorporando a noção de benefícios advindos do uso das TIC em termos de participação social.

De acordo com Kalplan (2005), em referência à eEurope Advisory Group, a inclusão digital significa:

Efetiva participação de indivíduos e comunidades em todas as dimensões básicas econômicas e de conhecimentos da sociedade, através de seus acessos às TIC [...]. Além disso, e-inclusão refere-se à graduação pela qual as TIC contribuem para equalizar e promover a participação na sociedade em todos os níveis: relacionamentos sociais, trabalho, cultura, participação política, etc. (KAPLAN, 2005, p. 7, tradução nossa).

O enfoque dessa definição centra-se na participação social facilitada por meio das TIC, estabelecendo-se correlação entre protagonismo social, econômico e os diferentes níveis de apropriação das informações e tecnologias. Considera-se, nesse sentido, a inclusão digital como um aspecto fundamental para a melhoria da equidade social e econômica de um indivíduo, de uma comunidade ou de uma nação. Por esse motivo, a formulação de políticas públicas de inclusão digital deve ser alvo de estudos e de investimentos governamentais. Conforme salientam Livingstone e Helspser (2008), as desigualdades digitais, socialmente engendradas, não podem ser superadas pelo esforço exclusivo do indivíduo, mas sim em uma dimensão política.

Com o objetivo de analisar os critérios de inclusão digital adotados em políticas públicas europeias, Almuwil, Weerakkody e El-Haddadeh (2011) elaboraram uma taxonomia dos diferentes modelos teóricos adotados nos últimos anos, defendendo a importância de indicadores para avaliação da e-inclusion. Entre os modelos citados pelos pesquisadores, destaca-se o estudo de Bradbrook e Fisher (2004), que analisa a 
inclusão digital sob cinco critérios, definidos como 5Cs: conectividade, que diz respeito ao acesso e à infraestrutura; capacitação, se referindo às habilidades para o uso das TIC; conteúdo, pertinente à relevância das informações acessadas; confiança, referente aos aspectos de segurança; e, por fim, a continuidade, isto é, a capacidade de fazer uso contínuo das TIC.

\section{Método}

Para análise dos desafios da inclusão digital na educação brasileira optou-se por uma pesquisa qualitativa exploratória bibliográfica, que tem por finalidade explorar o tema e construir hipóteses (cf. GIL, 2007). A categorização dos dados baseia-se nos critérios de inclusão digital supramencionados, estabelecidos por Bradbrook e Fisher (2004), os 5Cs: conectividade, capacitação, conteúdo, confiança e continuidade. Além desses cinco critérios, elegeu-se dois outros adicionais: um relacionado à proficiência em leitura e escrita, e o outro, considerando a educação inclusiva das pessoas com deficiência. Os sete desafios elencados foram cotejados com atuais estudos sobre o uso das TIC e sua relação com a educação brasileira.

\section{Discussão: os sete desafios da inclusão digital}

Os desafios da inclusão digital estão intrinsecamente relacionados aos aspectos econômicos, sociais, educacionais e culturais mais amplos. Conforme salientou Livingstone e Helspser (2008), as políticas de enfrentamento das desigualdades sociais possuem impacto nas discrepâncias de acesso às TIC. Por outro lado, atualmente, não é mais viável pensar em inclusão social sem levar em conta a dimensão do acesso e da garantia de bom aproveitamento dos dispositivos digitais em prol da cidadania. Deste modo, a seleção dos sete desafios foi realizada sob a perspectiva educacional, mas não se descarta a importância de políticas sociais inclusivas mais abrangentes.

\section{Melhoria da proficiência em leitura e escrita dos alunos brasileiros}

É indiscutível que o Brasil esteja enfrentando sérios problemas na educação básica, e o baixo desempenho dos alunos brasileiros nas avaliações do Programa Internacional de Avaliação de Alunos (PISA), realizadas pela Organização para Cooperação e Desenvolvimento Econômico (OCDE), constitui um dos indicadores da 
situação crítica e persistente. No ano de 2015 mantivemos a tradição dos piores resultados, ocupando a $59^{\mathrm{a}}$ posição no quesito de leitura. Mais da metade dos alunos que fizeram a prova não alcançaram o nível 2 de leitura, ficando nos níveis $1 \mathrm{~A}, 1 \mathrm{~B}$ ou abaixo de 1. Essa prova é aplicada em estudantes com idade de 15 anos matriculados nas escolas públicas e privadas do país (INSTITUTO NACIONAL DE ESTUDOS E PESQUISAS EDUCACIONAIS ANÍSIO TEIXERIA; ORGANIZAÇÃO PARA COOPERAÇÃO E DESENVOLVIMENTO ECONÔMICO, 2016). Embora esse tipo de avaliação em larga escola possa ser questionável do ponto de vista da educação comparada, os resultados corroboram a percepção empírica de que os estudantes brasileiros apresentam muita dificuldade na leitura e compreensão de texto.

Além da baixa proficiência em leitura, persiste o grave problema do analfabetismo na população adulta brasileira. De acordo com a Pesquisa Nacional por Amostra de Domicílios (PNAD), em 2015, aproximadamente 8\% das pessoas com 15 anos ou mais eram analfabetas (INSTITUTO BRASILEIRO DE GEOGRAFIA E ESTATÍSTICA). Esses dados do IBGE são assustadores, indicando que o analfabetismo entre adultos persiste de maneira crônica, afetando por volta de 12,9 milhões de pessoas e contribuindo para a perpetuação do problema nas crianças e jovens, pois, filhos de pais analfabetos podem ter menores expectativas escolares. Claro que isso não é uma regra, apenas uma tendência que deve ser considerada por educadores para que possa ser combatida.

O letramento digital, definido como "a capacidade de o indivíduo responder adequadamente às demandas sociais que envolvem a utilização de recursos tecnológicos e da escrita no meio digital" (SILVA, 2011, sem paginação), possui estreita relação com a alfabetização.

De acordo com Sorj (2003), a inclusão digital envolve diferentes tipos de apropriação dos recursos tecnológicos, incluindo uma forma passiva e ativa de se relacionar com as TIC. Com relação à apropriação ativa, o autor destaca três níveis: o primeiro refere-se à alfabetização digital pela qual o indivíduo aprende a usar os aplicativos básicos. Um segundo nível diz respeito à capacidade de usar a informática como meio de desenvolvimento intelectual e profissional. O terceiro nível envolve a produção de conteúdo, isto é, o uso das TIC para resolução de problemas.

Para que os estudantes consigam passar de meros usuários passivos a ativos, é desejável que tenham domínio prévio da escrita e da leitura. Nos estudos empreendidos por Prioste (2016a), sobre o adolescente e a internet, identificou-se um grande número 
de adolescentes que estavam no último ano do Ensino Fundamental e apresentavam uma alfabetização precária, sendo que alguns deles eram incapazes de ler palavras simples ou de compreender uma frase escrita de um assunto do cotidiano. A maior parte dos jovens utilizava a internet apenas para jogar, assistir vídeos, interagir nas redes sociais e nas websites de pornografia. De um modo geral, eles não conseguiam realizar pesquisas mais complexas sobre conteúdos educacionais ou criar um blog de maneira autônoma, pois apresentavam limitações na alfabetização.

Auvertlot et al. (2011), baseando-se nas evidências das pesquisas sobre desigualdade na educação, realizadas pelo sociólogo Paul Attewell, observaram que as crianças e jovens com problemas na leitura e na escrita eram as que possuíam maiores dificuldades para realizar pesquisas na internet. Além disso, ressaltaram que as crianças originárias de lares mais pobres demonstravam uma tendência de se contentar com as atividades de diversão, enquanto as crianças com melhores condições socioeconômicas eram mais ativas, conseguindo acumular informações e adquirir saberes a partir de suas interações virtuais.

No Brasil, o fato de um adolescente concluir o Ensino Fundamental no prazo previsto não significa que ele teve uma boa escolarização. Tem sido comum encontrarmos adolescentes que terminam a educação básica permanecendo praticamente analfabetos. É preciso considerar que, embora nossas políticas de ampliação do acesso e permanência dos estudantes na educação básica tenham avançado, os níveis de qualidade na educação ainda constituem um grande desafio. De acordo com Czernisz e Ruiz (2014), a noção de qualidade educacional nas políticas públicas brasileiras permanece ligada aos índices de avaliação de larga escala e ao mercado, pois na perspectiva neoliberal o que interessa são os indicadores quantitativos, mais do que os qualitativos.

Podemos concluir que, para além da pretensão política de equipar as crianças com sofisticados dispositivos de informática, é imprescindível investir em ações que tenham impacto na proficiência em leitura e escrita, para, assim, minimizar os riscos de que o laptop ou o tablet se transforme em mais um objeto de distração, desprovido de função educacional e social. Cabe lembrar que uma gigantesca indústria de diversões audiovisuais trabalha no sentido de formar precocemente consumidores assíduos.

\section{Promoção de adequada infraestrutura tecnológica nas escolas públicas}


$\mathrm{O}$ acesso às TIC merece especial atenção no que se refere ao contexto educacional, uma vez que importantes desigualdades são engendradas em decorrência do baixo ou do inadequado investimento em infraestrutura tecnológica nas escolas públicas. Uma pesquisa realizada pelo CGI revelou que, segundo a opinião dos professores, o principal limitador do uso do computador e da internet nas escolas públicas ainda era a falta de infraestrutura. A média de 22 computadores por escola, sendo que, apenas 19 estão em funcionamento, era insignificante em face do excessivo número de alunos, o que dificultava o uso das TIC nas atividades pedagógicas do cotidiano (COMITÊ GESTOR DA INTERNET NO BRASIL, 2013a). Um estudo realizado com professores da rede pública do município de Piracicaba, no estado de São Paulo, revelou que, embora a gestão pública tenha feito esforços no sentido de oferecer infraestrutura de computadores às escolas, muitas vezes os equipamentos nem eram retirados da caixa, ou não passavam por manutenção adequada para que fossem usados nas práticas pedagógicas (CUNHA; BIZELLI, 2016).

Uma pesquisa realizada pelo Instituto da Unesco (UIS) sobre as TIC na educação dos países da América Latina e Caribe analisou o número médio de alunos por computador, o learner to computer ratio (LCR), e identificou que o Brasil possuía, em média, 25 alunos para um computador na educação primária e 19 na educação secundária. No Chile, essa proporção era de 8 e 9, respectivamente, enquanto no Uruguai cada aluno tinha seu próprio computador, pois foi o primeiro país a adotar o One Laptop per Child (WALLET, 2013).

O número de alunos por computador tem sido considerado um indicador do investimento governamental em programas de inclusão digital, contudo, infraestrutura em informática não necessariamente precisa começar pela distribuição de laptops às crianças. Os benefícios dos programas One Laptop per Child são relativos conforme sugerem algumas pesquisas. Wallet (2013) analisou um recente estudo realizado no Peru sobre o programa One Laptop per Child, e constatou que a referida pesquisa não foi conclusiva sobre o impacto positivo na aprendizagem das crianças. No Brasil, o Projeto Um Computador por Aluno (UCA) também tem sido alvo de questionamentos sobre sua eficácia. A pesquisa de avaliação de impacto realizada por Lavinas e Veiga (2013) em seis municípios com implantação do projeto revelou baixo índice de aproveitamento, evidenciando graves problemas principalmente quanto à infraestrutura (por exemplo: falta de armários, de rede elétrica satisfatória e de conexão à internet), 
bem como deficiências na formação dos professores. Deste modo, o projeto não promoveu as mudanças esperadas no processo de ensino e de aprendizagem.

Com resultados também insatisfatórios, vale destacar o Programa Nacional de Tecnologia Educacional (ProInfo), criado com o intuito de promover melhoria na educação por meio do uso de ferramentas tecnológicas. De acordo com Silva (2011), o programa não tem causado impacto na qualidade de ensino do país, pois questões de base - por exemplo, o investimento nos professores -, não têm sido enfrentadas pelo poder público.

Gautier e Vergner (2012) consideram que trocar os cadernos por computadores, ou o quadro negro pela lousa digital, por si só, não implica grande impacto na educação. Por outro lado, dispor de um computador em sala de aula com acesso permanente às enciclopédias virtuais produz efeitos pedagogicamente mais interessantes. Defendem que os dispositivos tecnológicos devem ser usados de maneira complementar e não substitutiva aos meios impressos. Além disso, reforçam a importância da formação cultural e tecnológica do professor.

Com relação à infraestrutura, concluímos sobre a importância de se oferecer melhores recursos digitais em sala de aula, incluindo o acesso à internet por parte dos professores. Quanto ao fornecimento de laptops direto aos alunos, é essencial estudos que comprovem sua eficácia, principalmente considerando os problemas relativos à indução de hábitos de consumo promovida pela indústria audiovisual, conforme identificado por Duarte (2007) e Prioste (2016a). Por outro lado, é inegável a necessidade de se aumentar o número de computadores por alunos nas escolas públicas, viabilizando atividades pedagógicas relevantes à formação crítica e socialmente inclusiva.

\section{Capacitação dos professores para o uso das TIC}

$\mathrm{O}$ acesso das crianças e adolescentes ao computador e à internet está cada vez mais intensificado, mas será que o uso frequente lhes garante o desenvolvimento de competências digitais que ampliam seu universo de conhecimentos?

Os estudos de Prioste (2016a) com adolescentes estudantes do último ano do ensino médio, de uma escola pública e de uma escola particular, revelou que o simples uso diário das TIC não garantia o desenvolvimento de habilidades que de fato pudessem ampliar o universo de conhecimentos e perspectivas futuras de empregabilidade e de 
participação social dos adolescente provenientes de família de baixa renda, uma vez que imperava um condicionamento, por parte da indústria audiovisual, para que eles permanecessem em atividades repetitivas de diversão.

Auvertlot et al. (2011) constatou que o desenvolvimento de habilidades em informática está bastante relacionado à condição profissional dos pais. Os adolescentes tidos como multitarefas, com maior domínio em informática, são majoritariamente provenientes de um meio econômico e cultural privilegiado, permitindo-os o acúmulo de competências e saberes. O mesmo não ocorre com os jovens de classes populares, que acabam usando as TIC de maneira restrita.

Ao considerarmos a emergência de uma nova modalidade de aprendizagem por meio das mídias digitais, torna-se imprescindível o ensino das TIC nas escolas públicas, pois a maioria dessas crianças não terão oportunidades de desenvolver habilidades de informática com seus familiares ou rede de contatos próximos (PRIOSTE, 2016b). Além disso, é essencial que os educadores estejam familiarizados com os ambientes digitais que atraem as crianças e adolescentes, podendo conduzir esses interesses para finalidades pedagógicas.

No Brasil, o uso das tecnologias na educação também esbarra na formação docente e nas condições de trabalho do professor. Uma pesquisa realizada com docentes de escolas públicas brasileiras identificou que $49 \%$ consideravam o uso de TIC como muito importante nos espaços escolares, e 39\%, como importante; porém, apenas $15 \%$ dos professores se sentiam preparados para adotar as TIC em suas práticas pedagógicas. Além da falta de capacitação, os professores destacavam a falta de condições de trabalho adequadas, de tempo para preparar aulas, tendo em vista que muitos docentes eram obrigados a acumularem cargos devido aos baixos salários recebidos (CUNHA; BIZELLI, 2016).

Um dos grandes entraves do projeto UCA foi a dificuldade na capacitação dos professores para o uso das tecnologias em sala de aula. A avaliação de Lavinas e Veiga (2013) constatou que, embora o projeto UCA tivesse oferecido capacitação presencial de 40 horas e atividades de ensino a distância aos professores, cerca de $70 \%$ dos participantes relataram dificuldades no uso do laptop. Após um ano de projeto, constatou-se subutilização dos equipamentos em sala de aula e problemas na implementação de uma pedagogia digital.

A capacitação dos professores para o uso das TIC, na visão de Raiça (2008), deve ser desenvolvida a partir do projeto político pedagógico da escola, integrando os 
recursos tecnológicos às práticas pedagógicas das diferentes disciplinas do currículo e não apenas um uso esporádico. Nesse sentido, o professor deve passar por diferentes letramentos digitais, compreendendo o funcionamento de diversos recursos para que possa, assim, incentivar seus alunos no uso ativo das tecnologias.

Na perspectiva de Silva (2011), um dos principais motivos do fracasso das políticas públicas de inclusão digital no Brasil refere-se ao baixo investimento no professor, não somente no que tange à capacitação no uso das tecnologias, mas sobretudo em melhores condições de trabalho, melhores salários e formação continuada. Portanto, para que ocorra uma efetiva apropriação das TIC nas práticas pedagógicas é necessário investir na melhoria da escola como um todo.

\section{Promoção de acesso aos conteúdos significativos de cidadania e empregabilidade}

A seleção de informações e de conteúdos constitui um imenso desafio aos educadores diante do incomensurável lixo virtual e da indução de hábitos realizada pela indústria audiovisual. Além disso, há o problema da fidedignidade das informações disponíveis nos buscadores. Cassin (2007), ao analisar o Google, concluiu que existe um mercado digital de palavras que são agrupadas segundo critérios mercadológicos e não de relevância científica.

Aqui nos vemos diante de três problema importantes e complementares: primeiramente, a baixa formação cultural e tecnológica dos professores, dificultando o acesso e o domínio de conteúdos importantes disponíveis no meio virtual. O segundo problema refere-se à questão curricular. $\mathrm{O}$ que é importante ser ensinado às crianças e jovens? Quais conteúdos serão relevantes para melhorar suas condições de vida no futuro? E quais são as condições do sistema de ensino para promover acesso aos conteúdos significativos? Por fim, o terceiro aspecto diz respeito ao dilema que os professores enfrentam cotidianamente ao considerar as preferências de seus alunos, ao mesmo tempo em que precisam auxiliá-los a desenvolver outros interesses e vislumbrar novas perspectivas de futuro.

Nas últimas décadas, as condições de ensino foram se deteriorando no Brasil, sobretudo a partir das políticas de progressão continuada, as quais, segundo Bizelli, Cunha e Pereira (2013) foram implantadas como forma de redução de custos governamentais com a educação básica, mesmo que suas justificativas tivessem cunho pedagógico progressista. Essas medidas não consideraram os saberes docentes e a 
cultura escolar, culminando em uma progressão automática que tem contribuído ao analfabetismo funcional entre adolescentes. Nessas condições, o acesso dos adolescentes aos conteúdos relevantes tem sido cada vez mais restrito.

Gautier e Vergner (2012) sublinham que a Sociedade do Conhecimento traz em seu bojo uma proletarização do espírito em decorrência da submissão ao capitalismo. Essa proletarização baseia-se em uma economia de competências e na desvalorização dos saberes. Portanto, a escola tem um papel essencial, que na visão dos autores consiste na "formação de capacidades cognitivas gerais, assim como na autonomia de seu uso, por meio de contato assíduo e estudo racionalizado das obras humanas do passado e do presente" (GAUTIER; VERGNER, 2012, p. 109, tradução nossa). Os autores sustentam a importância de uma formação cultural ampla e crítica que se oponha à tendência de formar consumidores das distrações imediatas. Argumentam que a escola deve contribuir para a formação de pessoas capazes de manter a atenção duradoura e de refletir sobre suas escolhas de maneira racional e sensível.

Sem refutar a importância de uma formação cultural ampla, humanística e crítica, acrescentamos a relevância de acesso aos conteúdos que favoreçam a empregabilidade, pois para os jovens das classes populares urge a necessidade de se incluírem no mercado de trabalho visando à melhoria do rendimento familiar. Um estudo realizado por Labarthe (2008) com jovens moradores da periferia da cidade de Marseille na França demonstrou que o domínio das TIC pode favorecer perspectivas de inclusão profissional. A equipe de Labarthe realizou oficinas profissionalizantes em um espaço destinado à inclusão digital. Esse espaço, inicialmente, era frequentado pelos adolescentes com o exclusivo interesse nos jogos, porém, com as intervenções educacionais, os jovens passaram a perceber possibilidades de usos das tecnologias visando à ampliação de perspectivas de trabalho.

\section{Melhoria da segurança e confiabilidade}

O debate sobre segurança e confiabilidade das TIC, especialmente da internet, é extenso e muito importante quando se trata de crianças e adolescentes, isto é, de pessoas em fase de desenvolvimento e com maior vulnerabilidade psíquica. Não se tem, nesse artigo, a pretensão de abordar a complexidade de fatores envolvendo esse debate, cabenos apenas o papel de assinalar a relevância dessa questão nas políticas públicas de 
inclusão digital, em níveis federal, estadual e municipal; bem como no projeto político pedagógico das escolas.

Com relação à internet, Desiderá e Zuben (2013) destacam os perigos de invasão de privacidade, de acesso aos conteúdos ofensivos na rede, bem como o de contato com pessoas mal-intencionadas. Os autores citam uma pesquisa na qual $23 \%$ das crianças e dos adolescentes, com idade entre 11 e 16 anos, usuários da internet, relataram ter conhecido uma pessoa por meio da rede; destes, $23 \%$ estabeleceram um contato pessoal. Por outro lado, apenas $1 \%$ dos pais relatou que o filho encontrou pessoalmente uma pessoa conhecida por meio da Internet. Esses dados revelam uma discrepância entre a percepção dos pais em relação à segurança de seus filhos e os riscos que as crianças e adolescentes efetivamente correm.

Nas pesquisas de Prioste (2016a), identificou-se que adolescentes, com idade entre 13 e 16 anos, frequentavam, assiduamente, websites de pornografia. $\mathrm{O}$ mais grave foi a constatação de que o acesso aos conteúdos pornográficos era proporcionado por um dos principais jornais da cidade de São Paulo. Nos chats com imagens eróticas, os adolescentes tinham contato com fotos e vídeos de pedofilia, de zoofilia e de violência sexual, além da possibilidade de estabelecerem conversações online com as pessoas que postavam tais imagens.

A ciberdependência e a dependência por games violentos são dois outros importantes riscos quase sempre menosprezados quando se trata da relação de crianças com as TIC. A significância desse risco decorre especialmente do impacto negativo que o uso desmedido de jogos e da internet pode ter na vida escolar. Para além da discussão se estaríamos diante de uma nova psicopatologia, de um vício ou, em se tratando de crianças e adolescentes, apenas de um "uso problemático", o fato é que a intensidade dessas atividades está, segundo Valleur e Matysiak (2011), se tornando um problema crescente nos últimos anos. Os autores observam que, diferentemente do adulto, as crianças e os adolescentes não conseguem colocar limites em si próprios, controlando o tempo que dispendem nas atividades lúdicas realizadas nos computadores, smartphones e videogames. Assim, eles podem ter prejuízos funcionais significativos se não houver intervenção das famílias e dos educadores, controlando e orientando o uso de computadores e da internet.

Prioste (2016b), em uma pesquisa com estudantes de escolas públicas, na faixa etária entre 8 e 10 anos, identificou que muitos meninos costumavam jogar Grand Theft Auto (GTA), um jogo proibido para menores de 18 anos devido às cenas de extrema 
violência, incluindo assassinatos, roubos e estupros. Observou ainda que alguns pais eram permissivos e pouco atentos às atividades online das crianças.

A Organização para Cooperação e Desenvolvimento Econômico (2012), reconhecendo a importância de se analisar os riscos e os benefícios da internet na infância, organizou em 2012 o relatório "The Protection of Children Online: recommendation of the OCDE Council - report on risk faced by children online and policies to protect them", no qual ressalta a importância de fomentar políticas públicas de proteção às crianças. Destacam uma grande quantidade de pesquisas que evidenciam os riscos de interações ilegais, de conselhos perniciosos, publicidade online para crianças, transações fraudulentas e riscos de exposição de informações privadas. Além disso, há um grande número de dados acerca da exposição aos conteúdos impróprios, especialmente sobre pornografia e cyberbullying.

Para a OCDE (2012), a proteção de crianças online deve se prioridade, no entanto é fundamental equilibrar riscos e oportunidades presentes na Internet. A elaboração de políticas públicas é complexa e exige que todos os stakehoders compartilhem responsabilidades o coordenem seus papéis.

\section{Estímulos e suporte à continuidade de acesso}

Outro aspecto importante destacado por Bradbrook e Fisher (2004) com relação aos critérios para inclusão digital refere-se à continuidade de uso das tecnologias. Os constantes avanços tecnológicos fazem com que os equipamentos se tornem obsoletos em pouco tempo, portanto, os grupos economicamente favorecidos usufruem das inovações rapidamente, enquanto os mais pobres permanecerão longo tempo com equipamentos desatualizados. Semelhante desigualdade ocorre entre as escolas particulares e públicas brasileiras.

A falta de suporte técnico de hardware e de software nas escolas pode comprometer a continuidade de uso, um sério problema identificado no UCA (MENESES, 2011). Por mais que o professor se esforce para melhorar suas habilidades em informática, alguns conhecimentos técnicos são bastante específicos e não cabe aos professores desenvolvê-los, necessitando de um suporte técnico contínuo e efetivo. 


\section{Adaptações tecnológicas e pedagógicas visando à inclusão das pessoas com deficiências}

Em face das políticas em educação inclusiva vigentes no Brasil desde a década de 1990, repercutindo em maior número de crianças com deficiência nas salas de aula regulares, é essencial que os programas de inclusão digital contemplem as necessidades específicas dessa população por meio de adaptações de equipamentos, softwares pedagógicos, bem como capacitação dos professores. Raiça (2008) ressalta a importância das tecnologias no processo de ensino e aprendizagem dos alunos com deficiência, observando que alguns equipamentos, programas e aplicativos podem fazer muita diferença na vida das crianças. A autora propõe que o uso das TIC direcionado à inclusão das pessoas com deficiência esteja contemplado no projeto político pedagógico e que os professores possam ser capacitados para a realização de tais atividades.

\section{Considerações finais}

Um maior acesso às TIC por parte dos estudantes brasileiros não possibilita, por si só, enriquecimento educacional, uma vez que gigantescos oligopólios tecnológicos induzem determinados usos direcionados à diversão e à formação de consumidores. Diante disso, a escola possui importante papel na formação cultural ampla e crítica, para que ao invés de uma submissão irrefletida aos imperativos tecnológicos e audiovisuais, os estudantes possam usar as TIC visando a uma maior participação social e melhoria de suas condições de vida.

O avanço em termos de infraestrutura tecnológica nas escolas públicas é um importante desafio a ser vencido no Brasil, contudo, a inclusão digital não pode ser reduzida ao acesso. Além de ampliar a infraestrutura de TIC nas escolas, é imperativa a necessidade de superar o analfabetismo que ainda faz parte da realidade brasileira, melhorando a proficiência em leitura e escrita, condições essas prioritárias para obtenção de benefícios no uso das tecnologias. Para tanto, o investimento na formação cultural e tecnológica do professor é essencial, bem como a melhoria em termos de salário e condições de trabalho. Com relação às condições de trabalho, destaca-se a importância de equipamentos com acesso à internet em cada sala de aula, além de tempo e capacitação docente para a realização de pesquisas e planejamento das atividades pedagógicas. 
O governo não pode se eximir do compromisso de elaboração e implementação de políticas públicas efetivas em inclusão digital para todos, contemplando as adaptações tecnológicas e pedagógicas necessárias à formação cidadã, incluindo as pessoas com deficiência. Além disso, é preciso um esforço coletivo no que tange à proteção das crianças e dos adolescentes em relação aos riscos implicados no uso das TIC, especialmente no que concerne à internet e à dependência em jogos violentos. Por fim, precisamos enfatizar a responsabilidade das instituições públicas em relação à garantia do desenvolvimento de habilidades no uso ativo das TIC visando à ampliação cultural e à empregabilidade, pois é um mito acreditar que os estudantes podem desenvolver competências complexas sozinhos. Lembremo-nos que a melhor proteção, em face da crescente exploração mercadológica que tem sido realizada por meio dos objetos tecnológicos, ainda é uma educação de qualidade e que resulte em inclusão social.

\section{REFERÊNCIAS}

ALMUWIL, A.; WEERAKKODY, V.; EL-HADDADEH, R. A conceptual study of the factors influecing e-inclusion. European, Mediterranean \& Middle Eastern Conference on Information Systems, 2011, Atenas. Disponível em: <http://www.iseing.org/emcis/EMCISWebsite/EMCIS2011\%20Proceedings/GOV6.pdf >. Acesso em: 10 jan. 2014.

AUVERLOT, D. ; HAMELIN, J. ; LEJEUNE, E. ; LOYER, J-L. et al. Le fossé numérique en France. França: Premier Ministre, Centre d'analyse stratégique, 2011. Disponível em: <http://www.strategie.gouv.fr/content/le-fosse-numerique-en-france>. Acesso em: 13 jan. 2017.

BAUMAN, Z. Globalização: as consequências humanas. Rio de Janeiro: Zahar, 1999.

BIZELli, J. L.; CUNHA, M. D.; PEREIRA, C. E. C. Impactos da progressão continuada na educação do estado de São Paulo. Revista on line de Políticas e Gestão Educacional, Araraquara/SP, v. 15. n. 1, p. 150-166, 2013.

BRADBROOK, G.; FISHER J. Digital equality: reviewing digital inclusion activity and mapping the way forwards. United Kingdom, mar. 2004. Disponível em: <http://www.citizensonline.org.uk/site/media/documents/939_DigitalEquality1.pdf $>$. Acesso em: 20 mar. 2012.

CASSIN, B. Google-moi: la deuxième mission de l'Amérique. Paris: Albin Michel, 2007. 
COMITÊ GESTOR DA INTERNET NO BRASIL. TIC Educação 2012: pesquisa sobre o uso das tecnologias de informação e comunicação nas escolas brasileiras. São Paulo: CGI, 2013a.

COMITE GESTOR DA INTERNET NO BRASIL. TIC domicílios e empresas: pesquisa sobre o uso das tecnologias da informação e comunicação no Brasil. São Paulo: CGI, 2015.

CUNHA, M. D.; BIZELLI, J. L. Caminhos para TIC em sala de aula sob a perspectiva dos professores. Revista on line de Políticas e Gestão Educacional, Araraquara, v. 20. n. 2, p. 282-300, 2016.

CZERNISZ, E. C. S.; RUIZ, M. J. F. Qualidade da educação básica nas conferências nacionais de educação (1990-2004). Revista on line de Políticas e Gestão Educacional, Araraquara, v. 16. n. 1, 2016.

DESIDERÁ, L.; ZUBEN, M.V. Crianças e adolescentes usando a internet com segurança. In: COMITÊ GESTOR DA INTERNET NO BRASIL. TIC Kids online Brasil: pesquisa sobre o uso da internet por crianças e adolescentes. São Paulo: CGI, 2013c. p. 65-73.

DUARTE, R. Teoria crítica da indústria cultural. Belo Horizonte: Editora UFMG, 2007.

GAUTIER, J. \& VERGNE. Quelle école pour la «société de la connaissance. In KAMBOUCHNER, D. et al. L'école, le numérique et la société qui vient. Paris: Mille et une nuits, 2012. p. 95-131.

GIDDENS, A. Mundo em descontrole: o que a globalização está fazendo de nós. Rio de Janeiro: Editora Record, 2007.

GIL, A. C. Como elaborar projetos de pesquisa. São Paulo: Atlas, 2002.

INSTITUTO NACIONAL DE ESTUDOS E PESQUISAS EDUCACIONAIS ANÍSIO TEIXERIA; ORGANIZAÇÃO PARA COOPERAÇÃO E DESENVOLVIMENTO ECONÔMICO. Brasil no Pisa 2015: análises e reflexões sobre o desempenho dos estudantes brasileiros. São Paulo: Fundação Santilana, 2016.

INSTITUTO BRASILEIRO DE ESTATÍSTICA. Brasil em síntese: taxa de analfabetismo das pessoas de 15 anos ou mais. Disponível em: http://brasilemsintese.ibge.gov.br/educacao/taxa-de-analfabetismo-das-pessoas-de-15anos-ou-mais.html. Acesso em: 20 fev. 2017.

INTERNATIONAL TELECOMMUNICATION UNION - ITU. Measuring the information society. Geneva, 2015. Disponível em: http://www.itu.int/en/ITUD/Statistics/Pages/publications/mis2015.aspx. Acesso em: 15 jan. 2017.

KAPLAN, D. E-Inclusion: new challenges and policy recommendations. Europe Advisory Group, Jul. 2005. Disponível em: <http://www.umic.pt/images/stories/ publicacoes/kaplan_report_einclusion_final_version.pdf >. Acesso em: 15 jan. 2017. 
LABARTHE, F. Les TIC de la démocratisation culturelle: principes d'action, accès en public et compétences plurielles: le cas de 1'Espace Culture Multimédia de La Friche de la Belle de Mai à Marseille. Tese (Doutorado - Sciences de l'information et de la communication), Université d'Avigon, Avignon, FR, 2008.

LAVINAS, L; VEIGA, A. Desafios do modelo brasileiro de inclusão digital pela escola. Cadernos de Pesquisa. São Paulo, vol. 43, n. 49, p. 542-569, 2013.

LIVINGSTONE, S.; HELSPER, E. Gradations in digital inclusion: children, young people and the digital divide. London: London School of Economics and Political Science, 2008.

MANCINELLI, E. E-Inclusion in the information society, 2007. Disponível em: <http://www.ittk.hu/netis/doc/ISCB_eng/10_Mancinelli_final.pdf>. Acesso em: 12 jan. 2014.

MENESES, S.C.P. Um computador por aluno: era da inclusão digital. In: XXII SBIE XVII WIE, Aracaju, 21 a 25 de novembro, 2011. Anais. Disponível em: <http://ceiesbc.tempsite.ws/pub/index.php/sbie/article/view/1656/1421>. Acesso em: 07 jan. 2014.

ORGANIZAÇAO PARA COOPERAÇÃO E DESENVOLVIMENTO ECONÔMICO. The protection of children online recommendation of the OCDE council: report on risk faced by children online and policies to protect them. Paris, 2012. Disponível em: http://www.oecd.org/sti/ieconomy/protectingchildrenonline.htm. Acesso em: 12 mar. 2017.

PRIOSTE, C. O adolescente e a internet: laços e embaraços no mundo virtual. São Paulo: Edusp, 2016.

PRIOSTE, C. Tecnología, educación e innovación: riesgos y oportunidades. Journal of Engineering and Technology, vol. 5, n. 2, p. 72-81, 2016b.

RAIÇA, D. Tecnologias e educação inclusiva. In RAIÇA, D. (Ed.) Tecnologias para a educação inclusiva. São Paulo: Avercamp, 2008.

SASSEN, S. Sociologia da globalização. São Paulo: Artmed, 2010.

SORJ, B. Brasil@povo.com: a luta contra a desigualdade na sociedade da informação. Rio de Janeiro: Jorge Zahar; Brasíia, DF: Unesco, 2003.

SILVA, A. C. Educação e tecnologia: entre o discurso e a prática. Ensaio: Avaliação de Políticas Públicas em Educação. Rio de Janeiro, v. 19, n. 72, p. 527-554, jul./set., 2011.

WALLET, P. Tecnologias da informação e comunicação (TIC) na América Latina e Caribe. In: COMITÊ GESTOR DA INTERNET NO BRASIL. TIC Educação 2012: pesquisa sobre o uso das tecnologias de informação e comunicação nas escolas brasileiras. São Paulo: CGI, 2013, p. 113-122. 
VALLEUR, M. ; MATYSIAK, J. C. Le désir malade: dans un monde libre et sans tabous. Paris: Éditions Jean-Claude Lattès, 2011.

\section{Como referenciar este artigo}

PRIOSTE, Cláudia.; RAIÇA, Darcy. Inclusão digital e os principais desafios educacionais brasileiros. Revista on line de Política e Gestão Educacional, Araraquara, v. 21, n. esp.1, p. 860-880, out./2017. Disponível em: <http://dx.doi.org/10.22633/rpge.v21.n.esp1.out.2017.10457>. E-ISSN:1519-9029.

Submetido em: 10/05/2017

Aprovação final em: 28/09/2017 